\title{
Microstructural Characterization of Some Turbine Blade Martensitic Stainless Steels
}

\begin{abstract}
ANDREI CONSTANTIN BERBECARU ${ }^{1}$, GEORGE COMAN ${ }^{1}$, CATALIN STEFAN GRADINARU ${ }^{1}$, MIRELA GABRIELA SOHACIUㄹ, CRISTIAN PREDESCU ${ }^{1}$, RUXANDRA ELENA DUMITRESCU², SORIN CIUCA ${ }^{2 *}$, IOANA ARINA GHERGHESCU2*

1Politehnica University of Bucharest, Materials Science and Engineering Faculty, Department of Metallic Materials Processing and Eco - Metallurgy, 313 Splaiul Independentei, 060042, Bucharest, Romania

${ }^{2}$ Politehnica University of Bucharest, Materials Science and Engineering Faculty, Department of Materials Science and Physical Metallurgy, 313 Splaiul Independentei, 060042 Bucharest, Romania
\end{abstract}

\begin{abstract}
The paper presents microstructural features of three stainless steels utilized in making hydropower turbine parts. Two of these steels were already used in producing these parts, the third one is newly conceived. Aiming better mechanical and corrosion resistance characteristics, steels were produced using an induction furnace with cold crucible under vacuum and argon atmosphere, striving for an inclusion - free state. Quenching and tempering heat treatments were subsequently applied. The microstructural investigations, carried-outby microhardess testing, optical and scanning electron microscopy (SEM) associated with energy dispersive spectrometry (EDS), were able to explain the structural modifications. Refined microstructures were found in the two first steels. Concerning the third one, a precipitation phenomenon of intermetallic compounds such as $\mathrm{Ni}_{3}(\mathrm{Ti}, \mathrm{Mo})$ was reported, similar to that encountered in the maraging steels class. Mechanical properties of this steel are very different from classic martensitic stainless steels ones. Specifically, after tempering the hardness values do not decrease as in other steels, but increase about 1.6 times. Thus a new steel category with duplex properties is reported.
\end{abstract}

Keywords: turbine rotor blade, new martensitic steel, maraging steel

In the recentyears, some hydropower turbine parts such as rotor blades came into attention due to their premature failure. These problems were identified in hydroelectric power plants on the river Olt, Romania.

The main aggregate within a hydropower plant remains the turbine, in which the blade rotor is the main device of the entire hydrotechnical construction.

Analyses of the possible causes of destruction of the rotor - blade assembly [1-4] identified four of them as being most probable: a) cavitation wear; b) abrasion wear; c) fatigue; d) material defects.

The main two causes that affect the integrity of the rotorpallet system remain wear through cavitation and abrasion [5].

The primary reasons that contribute to increasing the mending durations are the occurrence of cracks and erosion on the rotor and blades. These are generally caused by material or manufacturing defects, fatigue or tensile/ compressive overloads. Erosion is caused by sand carried along in the turbine together with water as well as by hydrodynamic cavitation phenomenon (cavitation erosion)

Cavitational erosion craters sometimes have depths of the order of millimeters. Thus, it is sometimes possible to perforate the affected areas of the hydraulic turbine blades, the most affected by cavitation erosion.

The most complex models for abrasion wear evaluation (wear rate in $\mathrm{mm} /$ year) consider that the phenomenon can be explained by two mechanisms: one caused by the deformation occurring in the hydroenergetic aggregate material due to the repeated collision with hard particles, when the material elasticity limit is exceeded and the other due to the action of cutting the hydroenergetic aggregate material by the moving particles.

Factors that generally influence the abrasion wear rate are: the shape and size of particulates attacking the material, the hardness of these particulates, the particulates concentration in the carrier fluid, the particulate velocity, the attack angle between these particulates and the material, the curvature of the attacked surface, the nature of the attacked material. From the point of view of the material designer, this latter factor is the most important.

The materials used in manufacturing hydropower rotor blades are stainless steels. The choice between the two main classes, austenitic and martensitic, is based on the need to confer a high enough hardness to withstand the impact of the water filled with particulates and a good corrosion resistance to the rotor blade.

Martensitic steels $(\mathrm{Cr}<16 \%, \mathrm{Ni}=2-6 \%, \mathrm{C}=0.1-0.5$ $\%)$ are the first choice but the corrosion resistance is not high enough [6, 7]. At the same time, the complex fatigue strains of the hydropower turbine leads to the need of conferring a higher hardness to the rotor blade material by precipitates existing inside the grain structure, by increasing the welding capability through nickel addition and reduction of the carbon content.

Austenitic steels $(\mathrm{Cr}=16-28 \%, \mathrm{Ni}=8-30 \%, \mathrm{C}<0.1$ $\%$ ) are better materials in respect of corrosion resistance, weldability, plasticity and creep resistance but they exhibit weaker mechanical properties. In order to increase the latter, a partial substitution of Ni with gammageneous elements such as $\mathrm{Mn}$ and $\mathrm{N}$ is needed, butwith a corrosion behavior fallout.

Duplex steels (ferrito-austenitic) are a better choice in terms of high traction and fatigue resistance, good weldability, good corrosion resistance under load, satisfactory corrosion resistance and lower cost than the austenitic class due to lower Ni content $(1.4-7 \%)[8,9]$. The aim is to increase the corrosion resistance of these alloys by adding Mo $(0.3-4 \%)$, and increasing the tensile strength by nitrogen addition. These alloying elements may confer a better hardness in the entire volume $(\mathrm{Mo}, \mathrm{N})$ or in

*email: sorin.ciuca@upb.ro, Phone: +40729950571; gherghescu_ioana@yahoo.com,Phone: +40722434756 
surface only ( $\mathrm{N}$ ) or may be responsible of the passivationrepassivation phenomenon during cavitation attacks (Mo) $[10,11]$.

Better characteristics of commonly chosen stainless steels are expected to be found when steel making is performed in an induction funace with cold copper crucible. One of the purposes of this paper is to present structural characteristics of the alloys made by the above mentioned steel making method. Moreover, efforts have been made to conceive a new stainless steel for hydropower turbine, also made in an induction furnace. This choice concerning the steel making method could eliminate all drawbacks induced by a defective casting structure.

\section{Experimental part}

Steels were made in an induction furnace with a cold copper crucible with an inner diameter of $35 \mathrm{~mm}$ and a capacity of $8-15 \mathrm{~cm}^{3}$ equipped with a casting plug. The working parameters of the furnace are: nominal power 25 $\mathrm{kW}$, frequency HF 100 - $400 \mathrm{kHz}$, apparent power $40 \mathrm{kVA}$, phase current $40 \mathrm{~A}$, power factor 0.92 , minimum water flow $12 \mathrm{l} / \mathrm{min}$, maximum inlet pressure: 7.5 bar, water inlet: $\max .24^{\circ} \mathrm{C}$. The maximum working temperature of the furnace is $2800^{\circ} \mathrm{C}$ and the vacuum system consists of a primary vacuum pumping station including a pump of min. $1.7 \mathrm{~m}^{3} / \mathrm{h}$ with a vacuum limit of $10^{-4} \mathrm{mbar}$ and a vacuum pump pumping station for secondary vacuum of $1 \times 10^{-8}$ mbar.

Two formerly used rotor blade stainless steels were T8NCUMC130 CS L03.009.0 and GX4CrNi13-4 (EN 10283). Their chemical compositions determined by optical spectroscopy were presented in the table 1 and table 2.
Their chemical compositions were also improved and are found in table 3 as P1 and P2 steels, respectively. For P1 steel, Ni content was raised from 1.325 to $4.34 \%$ and the $\mathrm{Cr}$ one was lowered from 13.453 to $11.78 \%$. Other changes were made in order to reach a compromise between the mechanical characteristics and the corrosion resistance behavior of these materials. An important observation refers to copper, which was not present in the new chemical compositions. Despite its good influence on the corrosion resistance, the mechanical properties are negatively affected. Anyway, the concept referring to copper favorable influence on the corrosion behavior is outdated nowadays and for this reason it has not been taken into account.

The chemical composition of the new P3 steel was established in order to obtain a resistant martensitic stainless steel, which responds to complex requests of the hydropower turbines.

Weight calculation of the raw materials was made in such a way as to obtain three steel ingots with the chemical composition shown in table 3 whose positioning in the Schaeffler diagram is shown in figure 1.

In P3 steel, small amounts of Ti ( 0.92 wt\%), were added [13]. The model was taken from the chemical composition of maraging steels, with which it is related. In maraging steels $\mathrm{Ti}$ is present because it favors the precipitation of $\mathrm{Ni}_{3} \mathrm{Ti}$ compounds which, together with $\mathrm{Ni}_{3} \mathrm{Co}$ compounds, generate the highest hardening effect [14, 15].

Ti should be added in a small quantity because the hardening mechanism induces a high level of internal stresses on the crystalline level, which could influence the corrosion resistance requested for the new designed steel.

Table 1

CHEMICAL COMPOSITION OF ROTOR BLADE STEEL NO.1 (FACTORY STEEL GRADE)

\begin{tabular}{|l|c|c|c|c|c|c|c|c|c|c|}
\hline \multirow{2}{*}{ Factory steel grade } & \multicolumn{9}{|c|}{ Content, wt \% } \\
\cline { 2 - 11 } & $\mathrm{C}$ & $\mathrm{Si}$ & $\mathrm{Mn}$ & $\mathrm{P}$ & $\mathrm{S}$ & $\mathrm{Cr}$ & $\mathrm{Ni}$ & $\mathrm{Mo}$ & $\mathrm{Cu}$ & $\mathrm{V}$ \\
\hline Rotor blade 1 & 0.074 & 0.332 & 0.595 & 0.016 & 0.022 & 13.453 & 1.325 & 0.066 & 1.295 & 0.029 \\
\hline T8NCuMC130 CS & $\max$. & $\max$. & $0.2 \div$ & $\max$. & $\max$. & $12.0 \div$ & $1.0 \div$ & - & $1.0 \div$ & - \\
L03.009.0 & 0.10 & 0.4 & 0.6 & 0.025 & 0.030 & 13.5 & 1.5 & - & 1.3 & - \\
\hline
\end{tabular}

Table 2

CHEMICAL COMPOSITION OF ROTOR BLADE STEEL NO.2 (FACTORY STEEL GRADE)

\begin{tabular}{|c|c|c|c|c|c|c|c|c|c|c|c|}
\hline \multirow{2}{*}{$\begin{array}{c}\text { Factory steel } \\
\text { grade }\end{array}$} & \multicolumn{10}{|c|}{ Content, wt \% } \\
\cline { 2 - 12 } & $\mathrm{C}$ & $\mathrm{Si}$ & $\mathrm{Mn}$ & $\mathrm{P}$ & $\mathrm{S}$ & $\mathrm{Cr}$ & $\mathrm{Mo}$ & $\mathrm{Ni}$ & $\mathrm{V}$ & $\mathrm{Al}$ & $\mathrm{Cu}$ \\
\hline Rotor blade 2 & 0.025 & 0.40 & 0.73 & 0.035 & 0.002 & 12.60 & 0.35 & 3.82 & 0.03 & 0.012 & 0.35 \\
\hline G-X4CrNi13-4 & $<0.06$ & $<1$ & $<1$ & $<0.035$ & -0.025 & $12-$ & $0.4-1$ & $3.5-$ & - & - & - \\
& & & & & & 13.5 & & 4.5 & & & - \\
\hline
\end{tabular}

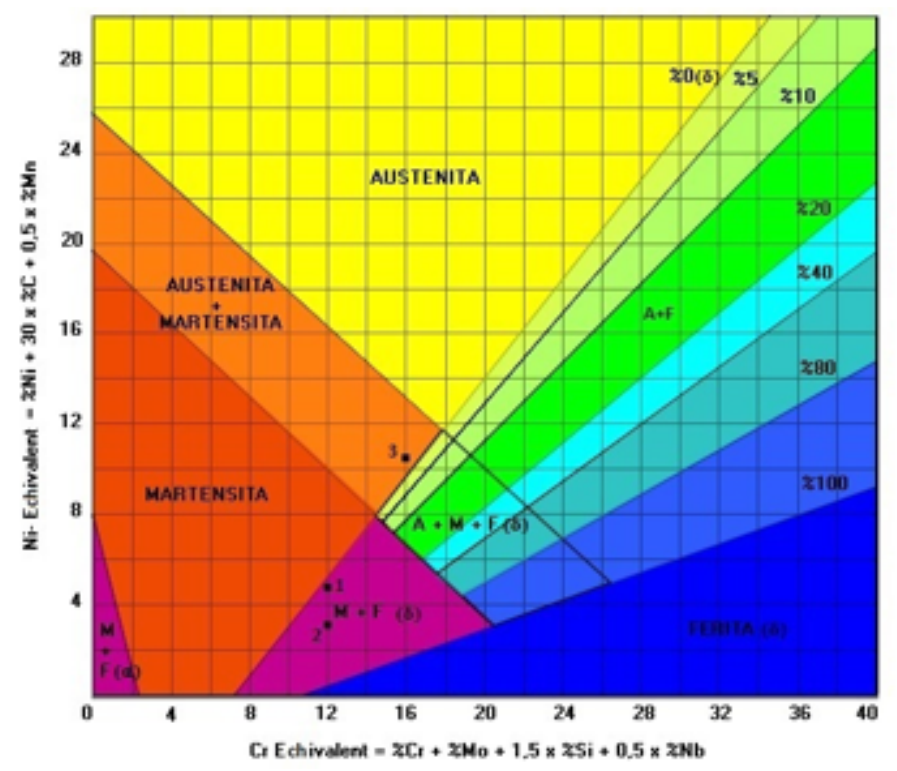

Fig. 1. Positioning in Schaeffler diagram of the three studied steels [12]. 
Table 3

CHEMICAL COMPOSITIONS IN wt\% OF P1, P2 AND P3 STEELS

\begin{tabular}{|c|c|c|c|c|c|c|c|c|c|c|c|c|c|c|c|}
\hline & $\mathrm{Cr}$ & $\mathbf{N i}$ & Mo & $\mathrm{Si}$ & $\mathbf{C u}$ & Mn & $\mathrm{Ti}$ & Al & $\mathbf{N b}$ & C & $\mathbf{V}$ & Co & $\mathbf{P}$ & $\mathrm{S}$ & $\mathrm{Fe}$ \\
\hline P1 & 11.78 & 4.34 & 0.002 & 0.182 & 0.078 & 0.550 & 0.001 & 0.0061 & 0.012 & 0.042 & 0.025 & 0.016 & 0.0079 & 0.0085 & 82.95 \\
\hline $\mathrm{P} 2$ & 12.05 & 3.85 & 1.024 & 0.393 & 0.170 & 0.676 & 0 & 0.0282 & 0.0438 & 0.0426 & 0.0081 & 0.0299 & 0.0287 & 0.0114 & 81.64 \\
\hline P3 & 9.92 & 9.61 & 5.07 & 0.295 & 0.147 & 0.351 & 0.923 & 0.049 & 0.0889 & 0.0223 & 0.0022 & 0.0356 & 0.0204 & 0.0204 & 73.8 \\
\hline
\end{tabular}

Table 4

TEMPERATURES OF HEAT TREATMENTS PERFORMED ON THE THREE STEELS

\begin{tabular}{|c|c|c|}
\hline & $\begin{array}{c}\text { Quenching } \\
\text { temperature, }{ }^{\circ} \mathrm{C}\end{array}$ & $\begin{array}{c}\text { Tempering (ageing) } \\
\text { temperature, }{ }^{\circ} \mathrm{C}\end{array}$ \\
\hline P1 & 1000 & 700 \\
\hline P2 & 1000 & 700 \\
\hline P3 & 1000 & 480 \\
\hline
\end{tabular}

Moreover, the presence of $\mathrm{Ti}$ is highly requested, because this element activates the formation of $\mathrm{Ni}_{3} \mathrm{Mo}$ compound, another intermetallic phase of the same family, which with a slightly diminished hardening effect does not strongly impair the corrosion resistance. In fact, precipitation typically consists in the mixed $\mathrm{Ni}_{3}(\mathrm{Ti}, \mathrm{Mo})$ compound [14, 15].

Taking into account all these data, the option was directed to a minimum value of $\sim 0.9 \mathrm{wt} \% \mathrm{Ti}$. Three batches, P1, P2, P3, were thus obtained having the chemical compositions presented in table 3 . 4.

Samples were submitted to the heat treatments (table

The three steels were characterized in terms of hardness and metallographic structure. Metallographic samples of cylindrical shape $x 14 \times 15 \mathrm{~mm}$ were prepared using a special Struers sample preparation line. Samples obtained from P1, P2 and P3 steels will be thus denominated samples 1,2 and 3.

The chemical reagent used for the three steels was the Marble reagent, whose chemical composition is: $10 \mathrm{~g}$ CuSO4, $50 \mathrm{~mL} \mathrm{HCl}, 50 \mathrm{~mL}$ distilled water.

The investigation tests were the following:

1. Hardness. Determination of the Vickers hardness of the three steels was performed using an Innovatest automated hardness testing system, with a force of $5 \mathrm{~N}$ and a holding period of $10 \mathrm{~s}$ as standard; the results of the sample measurements in quenched and tempered state are presented below.

2. Optical microscopy analysis. Samples P1, P2, P3 of the three steels, grounded, polished and etched with a specific reagent were analyzed using an Olympus-type BX51M optical microscope at 200 and 500 magnifications.

3. Scanning electron microscopy (SEM) associated with EDX analysis gave the following results:

- SEM images produced by secondary electrons;

- Backscattered electron imaging, wherein the brightness of the constituent elements is proportional to the square of the atomic number $\left(Z^{2}\right)$;

- EDX spectra, showing the presence of various chemical elements in the analyzed particle;

- Chemical composition of several analyzed microzones of the microstructure;

This information was obtained by examining the samples in a scanning electron microscope FEl Quanta FEG 450 having the following working parameters: voltage $30 \mathrm{kV}$, spot $5.5 \mathrm{~mm}$ and working distance $10 \mathrm{~mm}$.

The samples were analyzed in a quenched and tempered state. It was considered appropriate to present the images recorded at a magnification power of 10000 times and the spot chemical analysis to be performed in areas with a more distinctive morphology.

\section{Results and discussions \\ Hardness results}

Regarding the hardness values resulted after quenching and tempering, they follow a path that justifies the transformations that have taken place. The average hardness values obtained after making / casting, quenching and tempering are presented in table 5.

For samples 1 and 2, the hardness after tempering returns to lower values as against these obtained after quenching. The decomposition of martensite on heating, with the elimination of internal stresses, contributes to this phenomenon suggesting a sequence of transformations similar to those that usually appear on tempering.

As for sample 3 we see an increase in hardness from $315 \mathrm{HV}_{05}$ to $486 \mathrm{HV}_{05}$, i.e. a multiplication of almost 1.6 times. We attribute these results to the precipitations that occur and which increase the hardness according to the precipitation hardening mechanism, a particular case of dispersion hardening. This is the fundamental phenomenon in the decomposition of supersaturated solid solutions, the basis of the ageing heat treatment [13].

\section{Structural investigations by optical microscopy}

In all samples, optical microscopy micrographs at small magnifications (200x) highlight mainly martensite-specific needle-like features. Medium magnification powers (500x) allow a better analysis of the structures. In the case of samples 1 and 2 along with the martensite specific structures, some bright, insular well-delimited regions of ferrite exist, confirming the ferito-martensitic structure of these steels and justifying the positioning of their chemical composition in the Schaeffler structural diagram. A slightly increased proportion of ferrite in the case of sample 2 is attributed to the additional amount of $\mathrm{Mo}$, an alphageneous element present in this steel.

Sample 3 (P3 steel), along with martensite zones, shows a light background attributed to austenite. In this case the austenitic-martensitic structure shown by the compositional positioning in the Schaeffler diagram is confirmed.

A detail to be mentioned is related to the orientation of martensite needles, which form rather parallel regions and not needles jointed two by two at acute angles. This morphollogy is termed lath martensite, which is specific to low carbon martensite in the case of the three studied steels.

Structural investigations by optical microscopy on quenched samples

The microstructural results obtained after quenching are illustrated in figures 2, 3, 4.

Images at small magnification powers (200x) of the quenched samples show in all cases structures that do

\begin{tabular}{|c|c|c|c|}
\hline Sample/Steel & HV0.5 cast & HVo.s quenched & HV0.5 quenched + tempered \\
\hline $1 / \mathrm{P} 1$ & 382 & 349 & 279 \\
\hline $2 / \mathrm{P} 2$ & 355 & 343 & 318 \\
\hline $3 / \mathrm{P} 3$ & 308 & 315 & 486 \\
\hline
\end{tabular}

Table 5

AVERAGE HARDNESS VALUES RESULTED AFTER CASTING, QUENCHING AND TEMPERING 


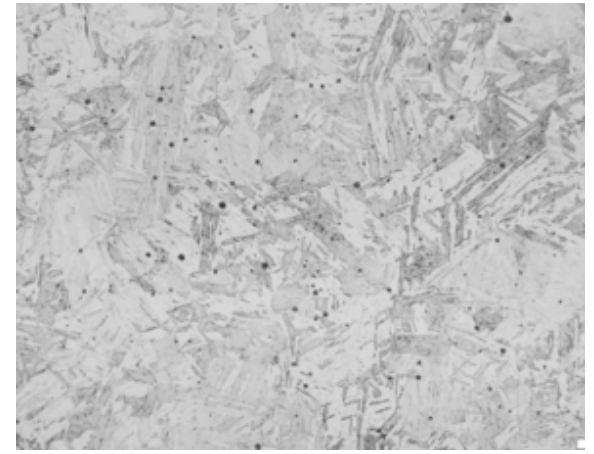

Fig.2 a. Optical micrograph of sample $P 1$, after quenching, Marble reagent, $200 x$

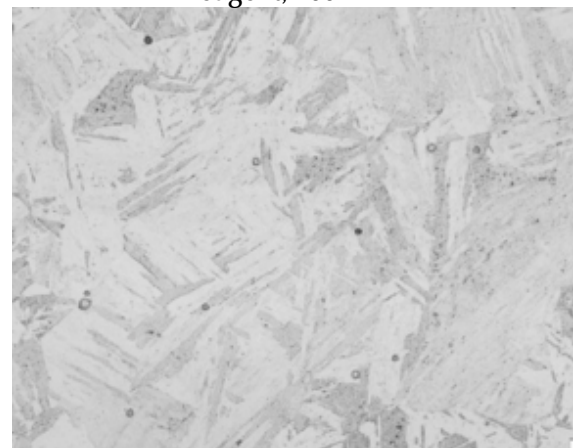

Fig.2 b. Optical micrograph of sample P1, after quenching, Marble reagent, $500 x$

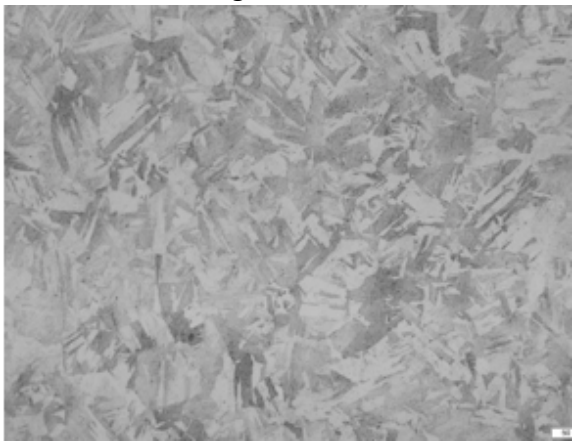

Fig.3 a. Optical micrograph of sample P2, after quenching, Marble reagent, 200x

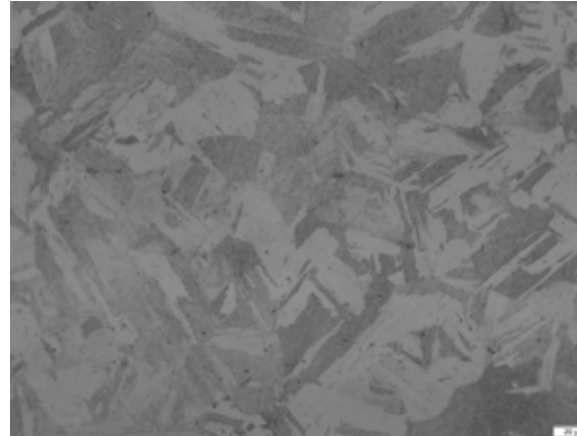

Fig.3 b. Optical micrograph of sample P2, after quenching, Marble reagent, 500x

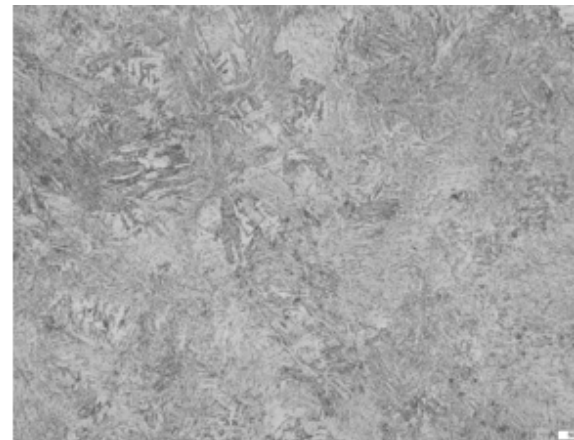

Fig. 4 a. Optical micrograph of sample P3, after quenching, Marble reagent, $200 \mathrm{x}$

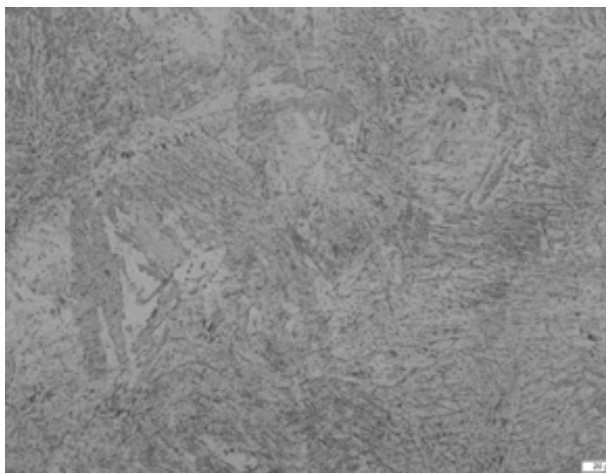

Fig.4 b. Optical micrograph of sample P3, after quenching, Marble reagent, $500 \mathrm{x}$

not differ greatly from the casting ones. The structures are martensitic, which demonstrates the self-hardening character of the steels.

An enhanced magnification power (500x) highlights the structural features. There is an important tendency to grain refining after hardening. Thus, for samples 1 and 2 the lengths of martensite needles are adjusted by reaching average dimensions of $80 \div 90 \mu \mathrm{m}$, as well as for sample 3 , where the needles average length is in the range $70 \div$ $80 \mu \mathrm{m}$.

Quenching also has an effect on the other phases besides martensite. For samples 1 and 2 ferrite islands are restricted, and in case of sample 3 the austenitic light background is reduced. These remarks are related to our other studies in casting state, which have already been reported [13].

All observations suggest higher mechanical properties, reinforcing the option to apply martensitic quenching after casting, even if the P3 steel is a self-hardening one.

\section{Structural investigations by optical microscopy on quenched and tempered samples}

It is emphasized that the tempering was performed at $700^{\circ} \mathrm{C}$ for samples 1 and 2, this temperature being recommended for stainless steels with predominantly martensitic structure [16]. For sample 3, the proposed steel has a composition that approaches Maraging steels, the tempering temperature being set at $480^{\circ} \mathrm{C}$. The option for this value is justified by the fact that martensite decomposition in this category of steels follows the sequence of ageing transformations rather than the tempering ones [14 - 17].

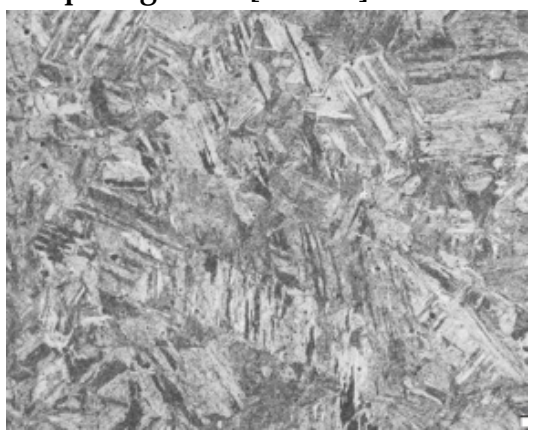

Fig.5 a. Optical micrograph of sample $P 1$, after quenching and tempering $\left(T=700^{\circ} \mathrm{C}\right)$, Marble reagent, 200x

Fig.5 b. Optical micrograph of sample $\mathrm{P} 1$, after quenching and tempering $\left(T=700^{\circ} \mathrm{C}\right)$,

Marble reagent, $500 \mathrm{x}$ 
Figures 5, 6 and 7 show the microstructures after the quenching and tempering heat treatment.

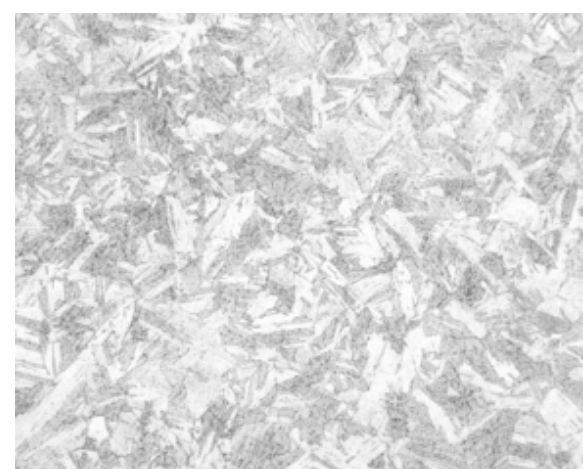

Fig.6 a. Optical micrograph of sample P2, after quenching and tempering $\left(T=700^{\circ} \mathrm{C}\right)$, Marble reagent, $200 \mathrm{x}$

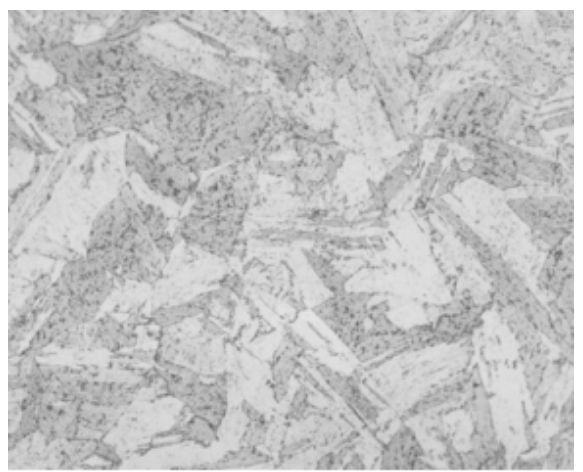

Fig.6 b. Optical micrograph of sample P2, after quenching and tempering $\left(T=700^{\circ} \mathrm{C}\right)$, Marble reagent, $500 \mathrm{x}$

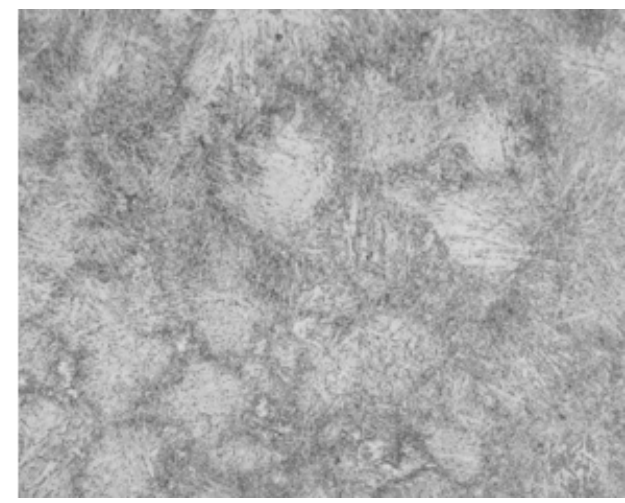

Fig.7 a. Optical micrograph of sample P3, after quenching and tempering $\left(T=480^{\circ} \mathrm{C}\right)$, Marble reagent, $200 \mathrm{x}$

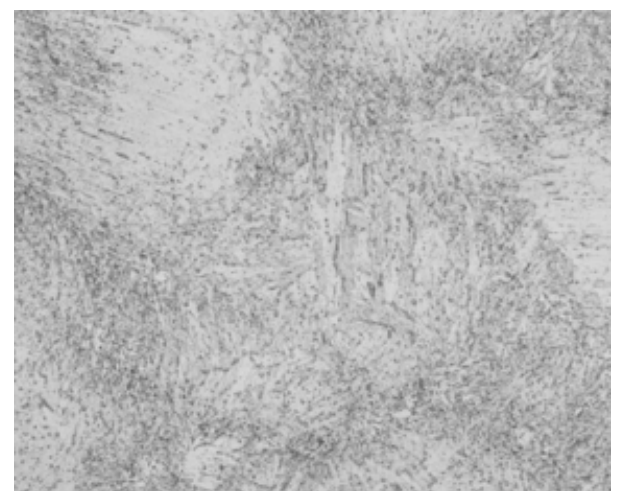

Fig.7 b. Optical micrograph of sample P3, after quenching and tempering $\left(T=480^{\circ} \mathrm{C}\right)$, Marble reagent, $500 \mathrm{x}$

In the abowe figures 5 and 6 (samples 1 and 2), the tempering structures made at small magnification (200x) maintain the overall acicular aspect. A more careful analysis determines that former needles of martensite do no longer have well-defined distributions but a slightly discontinuous contour.
The 500x magnification microstructures clarify the tendency of martensite decomposition in which the resulting precipitates exhibit an acicular shape. Some of the precipitates have a punctual, well confined appearance, while others suggest a transient stage of formation with precipitates-matrix semi-coherent boundaries.

Regarding sample 3 , the tendency to precipitate is much more intense, the particles shape being spherical. They are also to be found along the former martensite needles. A more pronounced precipitation predisposition can be determined along the darker circular contour signaled in both micrographs recorded at 200x and at 500x. The stronger precipitation action in the area suggests the existence of phasic heterogeneous micro-areas, in fact a former austenitic grain boundary interfering in the martensite formation.

It is well-known that grain boundaries are preferential areas where diffusion takes place more intensely, facilitating the formation of new phases by precipitation. The nature of the grain boundary or the nature of the precipitations will be determined by the scanning electron microscopy studies.

Structural and Compositional Investigations by Scanning Electron Microscopy (SEM) associated with Energy Dispersive $X$-ray Spectroscopy (EDS) on quenched and tempered samples

Significant changes in mechanical properties were reported after tempering. If the hardness for the first two samples dropped (sample 1 from $349 \mathrm{HV}_{0.5}$ to $280 \mathrm{HV}_{0.5}$, sample 2 from $343 \mathrm{HV}_{05}$ to $318 \mathrm{HV}_{05}$ ) in sample 3, the hardness increased (from $315 \mathrm{HV}_{0.5}$ to $486 \mathrm{HV}_{0.5}$ ). Certain structural changes were observed by optical microscopy but they can be more accurately analyzed according to the more complex data provided by the SEM-EDS analysis.

The micrographs in figure $8 \mathrm{a}$ and $\mathrm{b}$ capture images still exhibiting needle-like morphology. Needles do no longer present that firm, continuous distribution, but have a tendency to slightly bend, to become discontinuous. In the same time, the surface becomes rougher, the protrusions of perpendicular martensite needles are more pronounced, suggesting the predisposition of the supersaturation elements to exit the solution and regroup in the form of intermetallic compounds precipitations. The carbon content being very low in both samples, no propensity of carbides precipitation is reported.

The backscattered electron images with the representative areas selected for analyzing the chemical composition as well as the elements distribution spectra in the analyzed area are presented in the following.

One may observe from image analyses (EDS spectra, local chemical composition) that both samples have close chemical compositions, it is not possible to detect precisely the occurrence of areas with tempering specific precipitates. As a main transformation phenomenon it is assumed that stress relief is the strongest effect, related to the decrease in hardness after quenching in both cases.

A tendency to regroup of the chemical composition main elements can be noticed. The Fe, $\mathrm{Cr}$, Ni (sample 1) and Fe, $\mathrm{Cr}$, Ni and Mo (sample 2) distribution images provide information regarding the transformations. Thus, it is detected a segregation predisposition for $\mathrm{Fe}, \mathrm{Ni}$ and even Mo; $\mathrm{Cr}$ will remain uniformly distributed, because the carbon content is low and there is no danger concerning the precipitation of $\mathrm{Cr}$-rich carbides.

The tempering temperature of $700^{\circ} \mathrm{C}$ was very judiciously chosen [17 - 20]. For temperatures between 


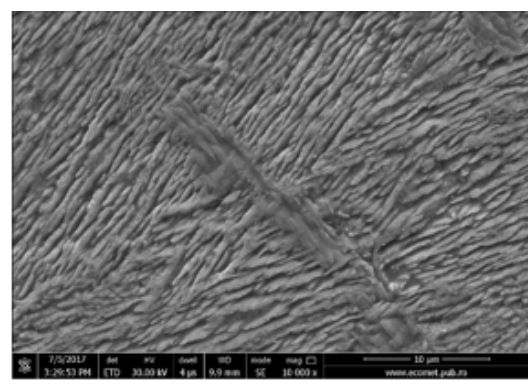

Fig.8 a. SEM micrograph (secondary electrons) of sample P1, quenched and tempered, $10000 \mathrm{x}$

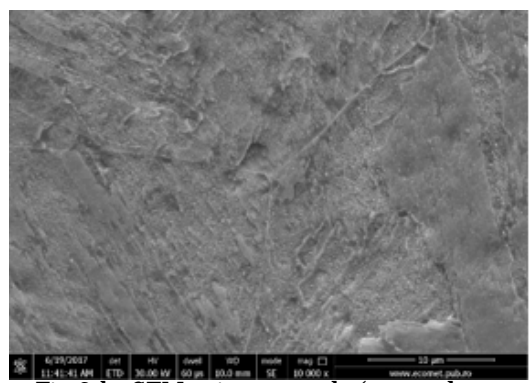

Fig. 8 b. SEM miccrograph (secondary electrons) of sample $\mathrm{P} 2$, quenched and tempered, 10000x

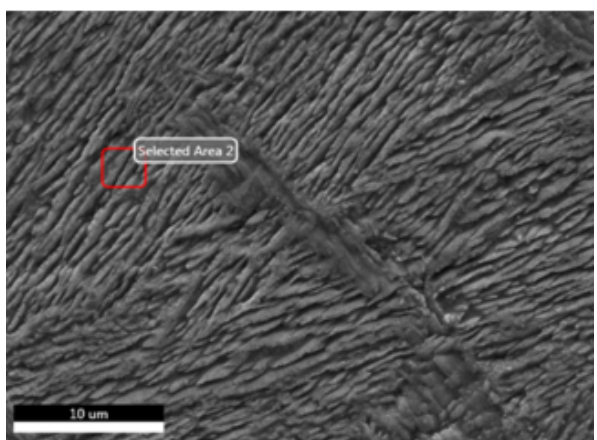

Fig. 9. Backscattered electron image (10000x) for sample 1 - quenched and tempered with composition analysis in the selected area (2)

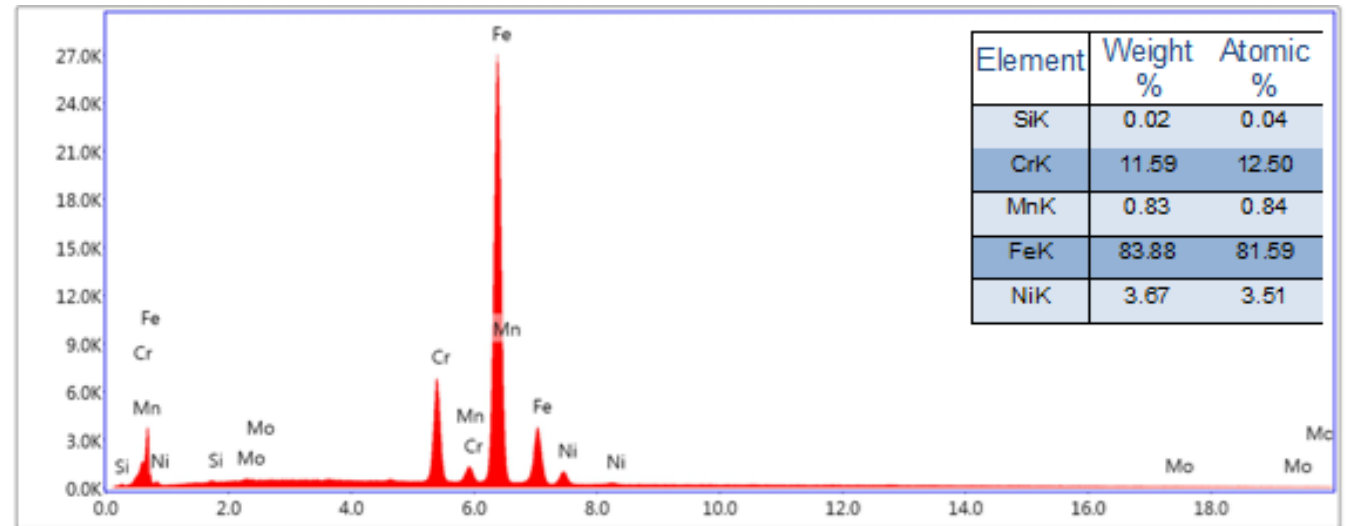

Lsec: $24.8 \quad 0$ Cnts $\quad 0.000 \mathrm{keV} \quad$ Det: Ortane Plus Det

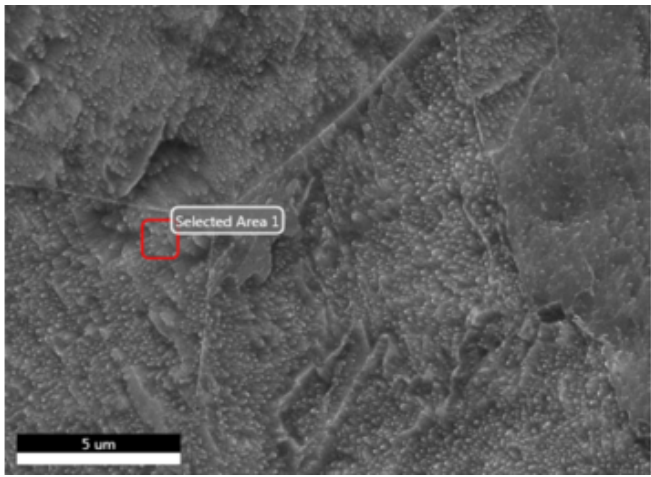

Fig. 10. EDS spectrum for sample 1 and spot chemical analysis in selected area (2)
Fig. 11. Backscattered electron image (10000x) for sample 2 quenched and tempered with composition analysis in the selected area (1)

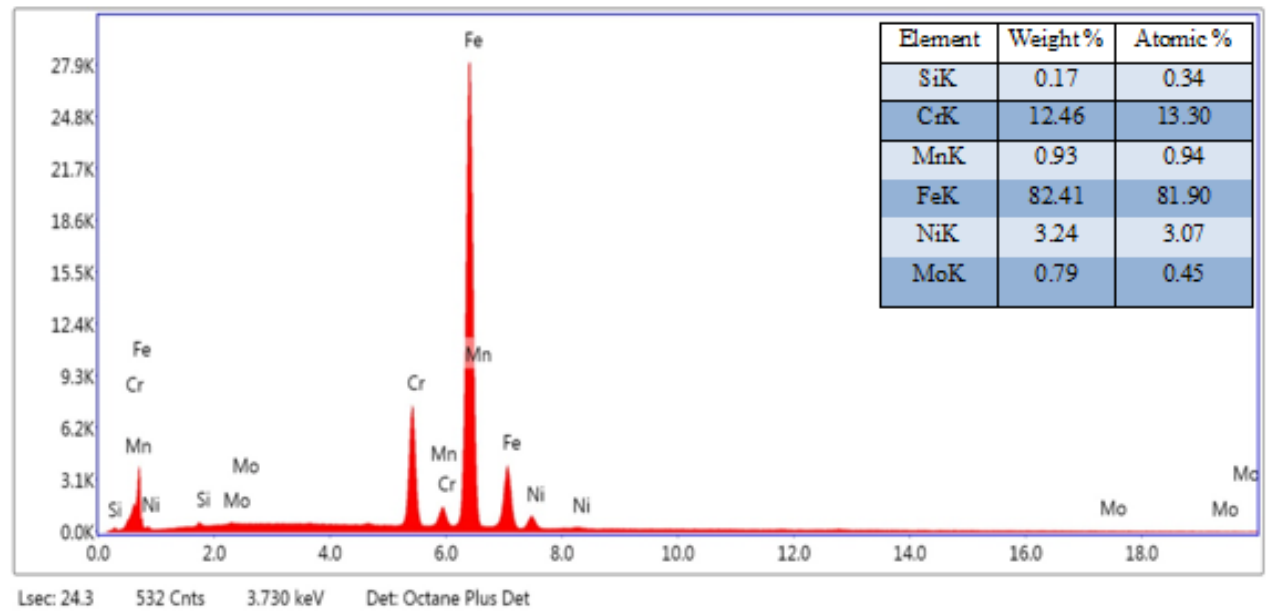

450 and $550^{\circ} \mathrm{C}$ (even $600^{\circ} \mathrm{C}$ ) in martensitic stainless steels (which have $\geq 12 \% \mathrm{Cr}$ ) there is a tendency to precipitate by a mechanism specific to spinodal decomposition, the $\delta^{\prime}$ rich $\mathrm{Cr}$ phase being therefore resulting. This w ould facilitate segregation in precipitated areas with depletion of adjacent zones to a much lower value, under the limit of $12 \%$ [18].

Since the spinodal dome (the miscibility gap) according to the Fe-Cr diagram has a maximum point of about $570^{\circ}$ - $580^{\circ} \mathrm{C}$, it results that heating at $700^{\circ} \mathrm{C}$ avoids this dangerous mechanism for the corrosion behavior.

The SEM image captures a main area (fund) with acicular distribution (martensitic), with elongated (light gray) areas arranged in a network corresponding to austenite butalso a distribution of bright globular particles with a denser distribution around the martensite needles (fig. 13). These particles can be attributed to the specific 


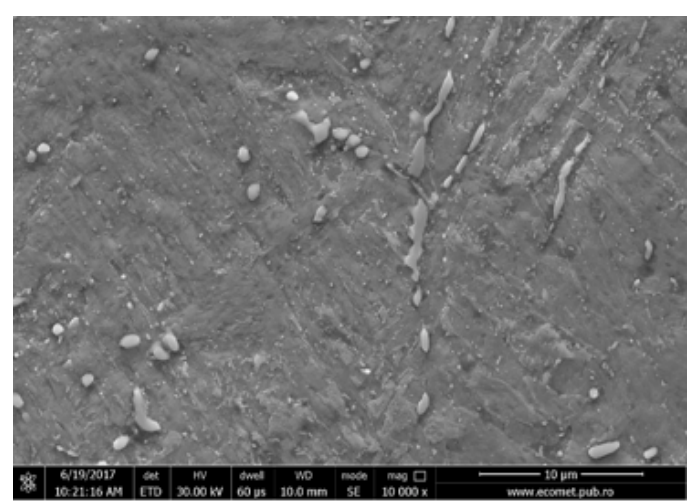

Fig. 13. SEM micrograph (secondary electrons) of sample 3, quenched and tempered, 10000x.

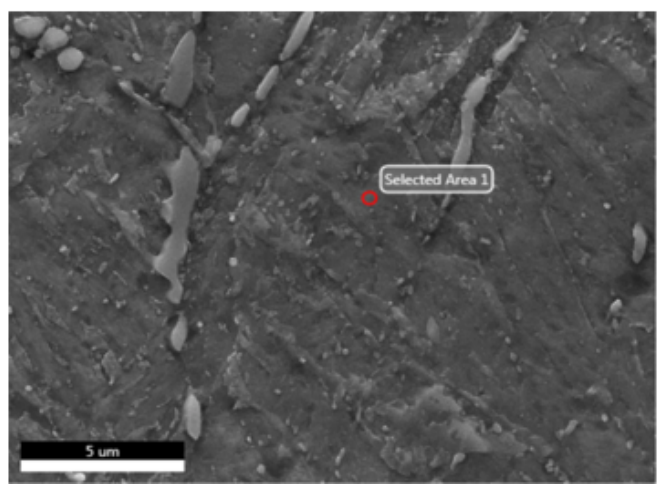

Fig. 14. Backscattered electron image of sample 3 indicating the selected area 1 precipitates that form upon tempering. However, associating the microstructural results with those resulting from the hardness tests ( $315 \mathrm{HV}_{0.5}$ after quenching or 486 $\mathrm{HV}_{05}$ after tempering), it can be stated that the present phenomena are more specific to ageing than tempering. In fact, the chemical composition of this steel was inspired from maraging steels.

Backscattered electron images, EDS spectroscopy and spot chemical analyses (figs. 14 - 17) were performed in two representative regions: in a higher homogeneity zone (selected area 1), butalso in a higher density of precipitated globular particles area (selected area 2).

Spot chemical analysis brings near-close values compared to chemical analysis by optical emission. However, Ni values may be below average (7.37\% vs. about $10 \%$ ) and Mo as well (3.13\% vs. about 5\%). Chromium exhibits a close composition ( 9.92 vs. 10\%) and Ti shows a slightly lower value $(0.75 \%$ vs. $0.9 \%)$ as against chemical analysis by optical emission.

In the rich precipitated particles area, the local chemical composition differs from the average chemical composition. The most important change is in the case of $\mathrm{Ni}$ that doubles (from about $10 \%$ to $20.57 \%$ ). Another concentration but not so important is for Mo (from $5 \%$ to $5.95 \%)$ and for Ti ( $1.08 \%$ vs. $0.8 \%)$. Observing this data and knowing that the hardening phase in the maraging steels is of the type $\mathrm{Ni}_{2} \mathrm{Me}$, where Me can be Ti, Co, Mo etc. [14, 15], a precise identification of these precipitates can be made. In the sample 3 of the new proposed steel small amounts of Ti (about $0.9 \%$ ) were added.

The new steel's chemical composition resembles to the chemical composition of maraging steels with which it is related. In maraging steels Ti is present because it is the promoter of $\mathrm{Ni}_{3} \mathrm{Ti}$ compound precipitation, generating

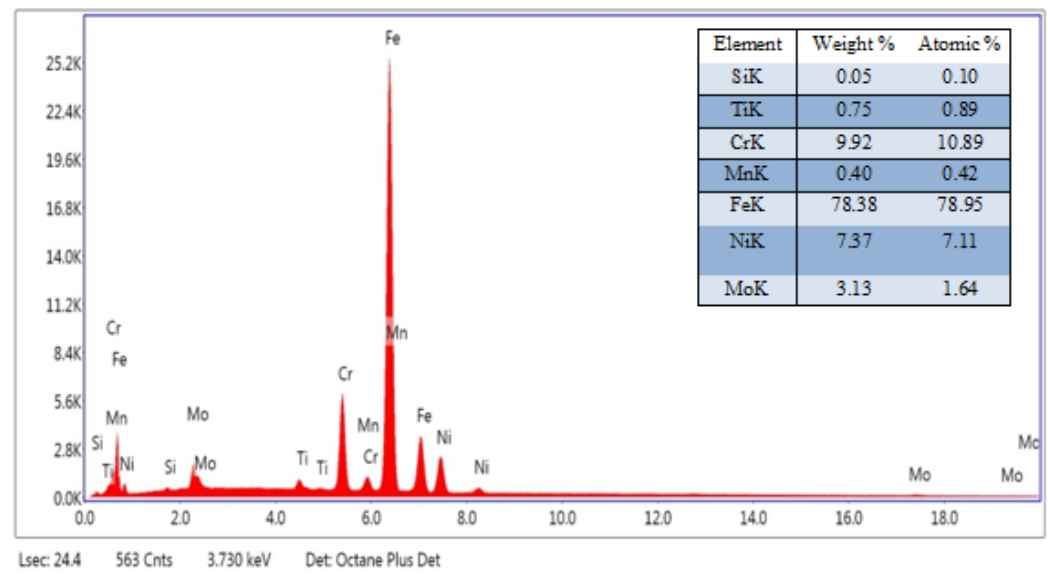

Fig. 15. EDS spectrum for sample 3 and spot chemical analysis in selected area (1)

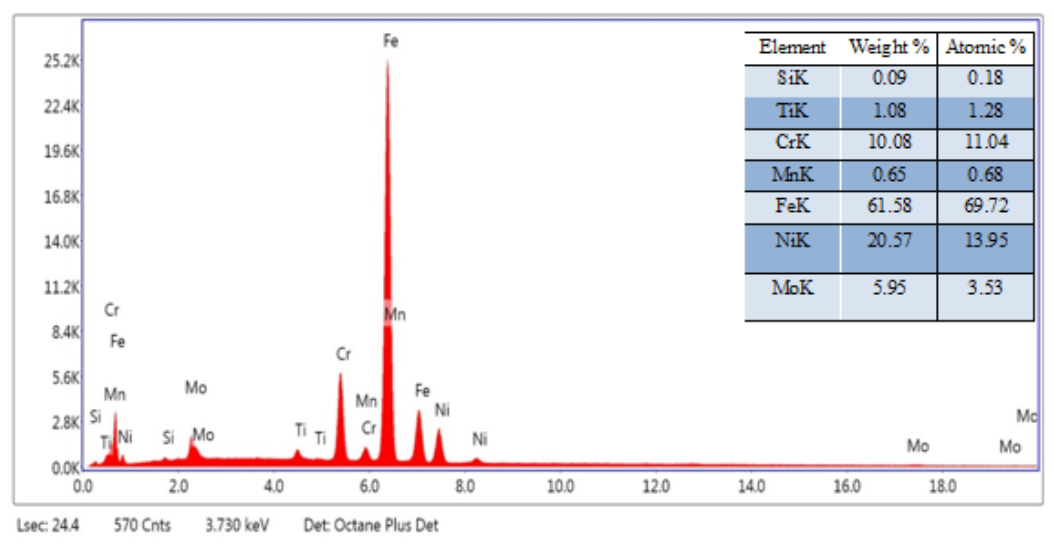

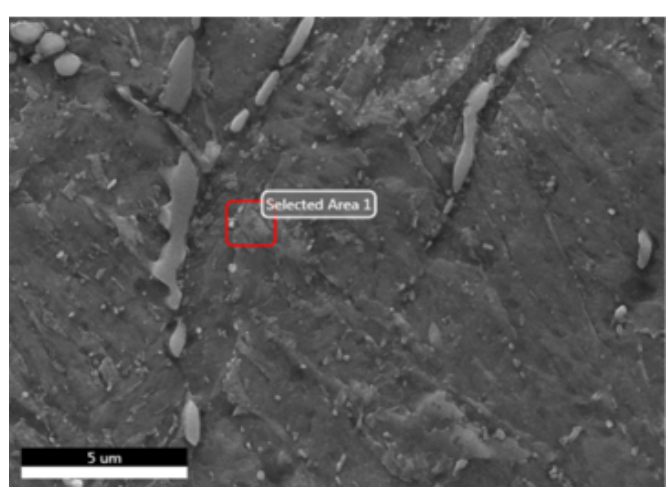

Fig. 16. Backscattered electron image of sample 3 indicating the selected area 2.

Fig. 17. EDS spectrum for sample 3 and spot chemical analysis in selected area (2) 
the highest hardening effect $[14,15]$. The dosage of Ti in the studied case was reduced to lower values $(\sim 0.9 \%)$ because the dispersing mechanism involved induces, at the crystalline level, strong internal stresses that could negatively influence the corrosion resistance of this steel. The presence of Ti stimulates the formation of the $\mathrm{Ni}_{3} \mathrm{Mo}$ compound, another intermetallic phase of the same family, which has a slightly diminished hardening effect without severely damaging the corrosion resistance value $[14,15]$.

Taking into account all these considerations, the atomic ratio at $\% \mathrm{Ni} /$ at $\% \mathrm{Ti}+$ at $\%$ Mo was calculated using the values from the table where the local compositional values were recorded: 13.95 at $\% \mathrm{Ni} / 1.28$ at $\% \mathrm{Ti}+3.53$ at $\% \mathrm{Mo}=$ 2.90.

On the basis of these considerations it can be stated that the hardening phases involved in the precipitation hardening mechanism are actually represented by the mixed intermetallic compound $\mathrm{Ni}_{3}(\mathrm{Ti}, \mathrm{Mo})$.

\section{Conclusions}

The structural analyses made by optical and electronic microscopy on the cast samples revealed similar structures of the three studied steels. As a common structural detail we find the martensitic acicular structure with a typical morphology for all low carbon martensites. Besides the martensitic areas, bright ferrite zones could also be located in samples 1 and 2 and a light austenitic background is found in sample 3 . These structural details confirmed the structural classes of the steels identified in the Schaeffler diagram.

The structures of the quenched samples highlight a refining effect of the heat treatment, the martensite needles are adjusted, becoming finer. At the same time, the proportion of phases accompanying martensite (ferrite for samples 1 and 2 and austenite in sample 3 ) is reduced. All observations suggest higher mechanical properties, reinforcing the option to apply martensitic quenching after casting even if they are self-hardening steels.

Local chemical analyses (EDS spectra, spot chemical analyses) demonstrate a high uniformity of distribution of the elements, indicating a punctual chemical composition almost in coincidence with the chemical composition determined by optical spectroscopy.

In regard to microstructure images after tempering (samples 1 and 2) and ageing (sample 3) the following statements may be made:

For samples 1 and 2, the structural aspect keeps a general acicular character, although the initial needles of martensite no longer retain the same well defined contour but are slightly discontinuous. It can be estimated that the main effect is a massive stress relief of the structure for both samples 1 and 2, the average hardness recording lower values. Local chemical analysis (EDS spectra, spot chemical analyses) again highlights an uniform chemical composition throughout the whole volume. This feature is very positive especially for $\mathrm{Cr}$ which maintains the same distribution uniformity providing a favorable corrosion resistance character.
Sample 3 brings more distinct structural aspects, attesting to the special character of the P3 steel. A more intense precipitation tendency is observed in micrographs (optical or electronic). Spotchemical analysis allowed the identification of these precipitates as complex intermetallic compounds, whose chemical formula is written as $\mathrm{Ni}_{3}(\mathrm{Ti}, \mathrm{MO})$. The increase in hardness after ageing from $315 \mathrm{HV}_{0.5}$ to nearly $486 \mathrm{HV}_{0.5}$ confirms the hardening effect of the compounds formed by a precipitation hardening mechanism, a particular mechanism of dispersion hardening.

\section{References}

1.PADHY, M.K., SAINI, R. P., RENEW SUST ENERG REV, no.12, 2008, p.1974.

2.SINGH, S.C., Operational problems and development of a new runner for silty water. International WP \& DC, November, 1990.

3.TONG, D., Cavitation and wear on hydraulic machines. International Water Power \& Dam Construction, April, 1981.

4.*** http://www.tev.ntnu.no/vk/publikasjoner/pdf/ArneKjolle/ chapter14.pdfS.

5.KUMAR, P., SAINI, R.P., RENEW SUST ENERG REV, 14, 2010, p.374.

6.SOHACIU, M., CIUCA, S., SAVASTRU, D., COMAN, G., PREDESCU, A., BERBECARU, A., COTRUT, C., MATEI, E., GHERGHESCU, I.A., PREDESCU, C., OPTOELECTRON ADV MAT, 10, Issue 3-4, 2016, p.259. 7.MATEI, E., PREDESCU, C., BERBECARU, A., PREDESCU, A.M., TRUSCA, R., DIG J NANOMATER BIOS, 6, no. 9, 2011, p. 1701.

8.LUCACCI, G., Steels and alloys for turbine blades in ultra-supercritical power plants, Materials for Ultra-Supercritical and Advanced UltraSupercritical Power Plant, 2017, p. 190.

9.PHANEENDRA, K.C., SHIBU, C., MEASUREMENT, 46, Issue 6, July 2013, p. 1880.

10.TANUMA, T., Development of last-stage long blades for steam turbines, Advances in Steam Turbines for Modern Power Plants, Woodhead Publishing, 2017, pag. 282.

11.MATEl, E., PREDESCU, A.M., VASILE, E., PREDESCU, C., OPTOELECTRON ADV MAT, 5, Issue 3, 2011, p. 298.

12. *** http://www.magmaw eld.com/stainless_steel_welding.html 13.COMAN, G., CIUCA, S., BERBECARU, A.C., PANTILIMON, M.C., SOHACIU, M.G., GRADINARU, C., PREDESCU, C., U POLITEH BUCH SER B, 79, Issue 4, 2017, p. 213.

14.CARTER, J.C.S., METALL TRANS, 1, 1970, p. 1556.

15.ANTOLOVICH, S., SAXENA, A., CHANANI, C.R., METALL TRANS, 5, 1974, p. 627.

16.LIU, Y., YE, D., YONG, Q., ZHAO, K., JIANG, W., J IRON STEEL RES INT, 18, 2011, p 65.

17.VISWANATHAN, U.K., DEY, G.K., ASUNDI, M.K., METALL TRANS, 24, 1993, p. 2431.

18.HUGUES, J., Vieillissement thermomecanique d'un acier inoxydable martensitique a durcissement structural, PhD Thesis, 2014, INP Toulouse.

19.RAABE, D., SANDLOBES, S., MILLAN, J., PONGE, D., ASSADI, H., HERBIG, M., CHOI, P.-P., ACTA MATER, 61, Issue 16, 2013, p. 6143. 20.RUSANESCU, C.O., RUSANESCU, M., ANGHELINA, F.V., OPTOELECTRON ADV MAT, 7, Issue: 11-12, 2013, p. 950

Manuscript received: 19.12 .2018 